\title{
Interactions of Methylenetetrahydrofolate Reductase C677T Polymorphism with Environmental Factors on Hypertension Susceptibility
}

\author{
Shujun Fan ${ }^{1,+}$, Boyi Yang ${ }^{2,+}$, Xueyuan Zhi ${ }^{1}$, Yanxun Wang ${ }^{3}$, Jian Wei ${ }^{4}$, Quanmei Zheng ${ }^{1}$ and \\ Guifan Sun ${ }^{1, *}$ \\ 1 Environment and Non-Communicable Disease Research Center, School of Public Health, \\ China Medical University, Shenyang 110013, China; fanfan0721ykl@163.com (S.F.); \\ zhixy90smile@126.com (X.Z.); qmzheng@mail.cmu.edu.cn (Q.Z.) \\ 2 Guangzhou Key Laboratory of Environmental Pollution and Health Risk Assessment, \\ Department of Preventive Medicine, School of Public Health, Sun Yat-sen University, Guangzhou 510080, \\ China; yangby23@mail.sysu.edu.cn \\ 3 Division of Molecular Preventive Medicine, Shanghai Institute of Targeted Therapy and Molecular Medicine, \\ Shanghai 200433, China; wangyanxun@genechina.com \\ 4 Brain Disease Center, Tianjin Dagang Oil Field General Hospital, Tianjin 300280, China; \\ weijiantianjin@163.com \\ * Correspondence: sungf@mail.cmu.edu.cn; Tel.: +86-24-2326-1744 \\ + These authors contributed equally to this work.
}

Academic Editor: Paul B. Tchounwou

Received: 21 March 2016; Accepted: 14 June 2016; Published: 17 June 2016

\begin{abstract}
Hypertension is considered to be the result of genes, environment, and their interactions. Among them age, sex, tobacco use, alcohol consumption, and being overweight/obesity are well documented environmental determinants, and methylenetetrahydrofolate reductase (MTHFR) C677T polymorphism is nominated as a potential genetic candidate. However, the synergistic effect of the MTHFR C677T polymorphism with these environmental factors on the risk of hypertension has received little attention. The aim of this study was to explore the associations of the MTHFR C677T polymorphism, environmental factors, and their interactions with hypertension predisposition in a Northern Chinese Han population. A total of 708 participants were enrolled in the study. The genotypes of the MTHFR C677T were determined by a TaqMan assay. We found that participants of an older age, being overweight/obesity, with a smoking habit, drinking habit, or carrying the 677T allele were at an increased risk of hypertension. Additionally, there existed marginally significant interactions of the polymorphism with age and overweight/obesity. However, future large, well-designed studies in Chinese and other populations, as well as mechanistic studies, are still needed to validate our findings, especially considering that the interactions observed in our study were only marginally significant.
\end{abstract}

Keywords: environmental factors; hypertension; interaction; MTHFR C677T

\section{Introduction}

Hypertension, the leading risk factor for cardiovascular diseases and premature death, has become a severe public health challenge worldwide. In China, the estimated prevalence of hypertension among adults has increased from $7.5 \%$ in 1979 to $25.2 \%$ in 2012 [1]. However, the exact pathophysiology of hypertension remains unclear, and multiple factors are thought to contribute to the development and progression of the disorder. Established environmental determinants of blood pressure levels include age, sex, tobacco use, sodium intake, alcohol consumption, dietary habits, being 
overweight/obesity, and dyslipidemia [2-4]. In addition to environmental factors, genetic factors also have been identified as modulators of hypertension. Hundreds of genes and polymorphisms have been hypothesized to be involved in the pathogenesis of hypertension, and it is estimated that $30 \%-40 \%$ of the variation in blood pressure could be attributed to heritability [5]. A recent genome-wide association study has linked genetic variation at eight loci with high blood pressure, including the gene encoding methylenetetrahydrofolate reductase (MTHFR), an enzyme catalyzing the reduction of 5,10-methylenetetrahydrofolate to 5-methyltetrahydrofolate [6]. The enzyme resides at an important metabolic branch point directing the distribution of folate derivatives to meet requirements for homocysteine and DNA methylation or for DNA and RNA biosynthesis. C677T is a common polymorphism in the MTHFR gene. The incidence of this mutation in the homozygous and heterozygous state is $43.9 \%$ and $23.2 \%$ in the Chinese population, respectively, which is higher compared with many other populations worldwide [7]. As a result of this polymorphism, the 677TT carriers have $30 \%$ and $677 \mathrm{CT}$ carriers have $60 \%$ of the wild-type (677CC) enzymatic activity, causing impaired remethylation of homocysteine to methionine and subsequent hyperhomocysteinemia, especially under conditions of low dietary folate [8]. Hyperhomocysteinemia has been linked to hypertension as it may induce arteriolar constriction, renal dysfunction, increased sodium reabsorption, and increase arterial stiffness and oxidative stress [9]. The 677T allele could also cause DNA hypomethylation [10], which has been involved in the pathogenesis of hypertension [11]. Therefore, the MTHFR C677T polymorphism is expected to be potentially associated with hypertension.

Previously, numerous epidemiological studies have explored the relationship of the MTHFR C677T polymorphism with hypertension, but the results were inconsistent [12]. Our previous large meta-analysis including 114 studies found that the polymorphism was significantly related to hypertension among East Asians and Caucasians, but not among Latinos, Black Africans, Indians, and Sri Lankans [12]. Several genome-wide association studies, mostly among Europeans, have identified more than 30 genomic loci linked to blood pressure levels [6,13]; however, subsequent genome-wide association studies among East Asians showed inconsistent results [14,15]. Cumulative effect of the genetic loci identified through these genome-wide association studies explained $<2.5 \%$ of systolic and diastolic blood pressure variance despite estimates of heritability of blood pressure of $30 \%-40 \%[5,13,16]$. These inconsistent observations may be explained by a number of hypotheses, with gene-environment interaction emerging as a strong candidate because genetic effects on blood pressure can be altered by environmental exposures via multiple biological pathways.

In recent years, greater emphasis has been placed on the joint effects of genetic and environmental factors on complex disease traits, including hypertension. Two recent studies respectively investigated gene-smoking and gene-alcohol interaction effects on blood pressure using genome-wide data from the Framingham Heart Study and identified several novel blood pressure loci $[4,16]$. Xi et al. investigated the effect of obesity on relationship of six genetic loci recently identified by genome-wide association studies with hypertension among Chinese children and found five loci were significantly associated with hypertension only in obese individuals [17]. A study in Brazil revealed that angiotensinogen Met235Thr and endothelial nitric oxide synthase Glu298Asp polymorphisms had interactions with smoking, sedentary lifestyle, elevated total cholesterol, and older age towards the development of hypertension [18]. For the MTHFR C677T polymorphism, its interaction with B-vitamins on cardiovascular diseases, hypertension, and blood pressure lowering has also been extensively investigated [19-21]. For example, Klerk et al. found that the 677TT genotype was associated with an increased risk of coronary heart disease in Europeans but not in North Americans, which was likely to be driven by differences in exposure to B-vitamins, especially folate intake [19]. In addition, Wilson and colleagues demonstrated that riboflavin supplementation is effective in reducing blood pressure specifically in individuals with the 677TT genotype [21]. However, the influence of other potential risk factors (such as age, being overweight/obesity, alcohol drinking, and cigarette smoking) on association between the MTHFR C677T polymorphism and the risk of hypertension received little attention, especially considering that these factors have been shown to, independently or in combination with the MTHFR C677T polymorphism, affect homocysteine levels [22]. Hence, we performed a cross-sectional 
study to explore the associations of some environmental factors, the MTHFR C677T polymorphism, and their interactions with hypertension predisposition in a Northern Chinese Han population.

\section{Materials and Methods}

\subsection{Study Population and Inclusion Criteria}

The study was carried out in the physical examination center of the Dagang Oil Field General Hospital, Tianjin Municipality. We used random number tables (by using SAS version 9.2, SAS Institute Inc., Cary, NC, USA) to select study subjects from persons who took regular health examinations during the period between 2010 and 2012. Inclusion criteria were as follows: (1) age $\geqslant 18$ years; (2) Han nationality; (3) without severe chronic or infectious diseases. In the beginning, 835 persons expressed an interest in our study and agreed to undergo a genotype determination. Then, based on the above inclusion criteria, 127 subjects were excluded, of which 75 had incomplete data and 52 reported histories of diabetes mellitus, cardiovascular diseases, renal diseases, myocardial infarction, or secondary hypertension. Finally, 708 participants were included in formal analysis (Table 1). The participants included both households and working populations in the Dagang Oil Field. The study was conducted in accordance with the Helsinki Declaration, and the protocols were approved by the ethics review committee of the China Medical University (Shenyang, China; Identification code: CMU 62073024; 15 July 2008). Informed consent was obtained from all participants prior to study entry.

Table 1. The characteristics of the study participants.

\begin{tabular}{|c|c|c|c|c|}
\hline Characteristics & Total & Hypertensive & Normotensive & $p$-Value \\
\hline \multicolumn{4}{|c|}{ Age (years), $n(\%)$} & \multirow{3}{*}{$<0.001$} \\
\hline$\leqslant 45$ & $350(49.44)$ & $66(30.84)$ & $284(57.49)$ & \\
\hline$>45$ & $358(50.56)$ & $148(69.16)$ & $210(42.51)$ & \\
\hline \multicolumn{5}{|c|}{ Mean age (years) } \\
\hline$\leqslant 45$ & $38.99 \pm 5.54$ & $39.70 \pm 4.97$ & $38.83 \pm 5.66$ & 0.251 \\
\hline$>45$ & $51.73 \pm 4.44$ & $52.34 \pm 4.38$ & $51.30 \pm 4.44$ & 0.027 \\
\hline \multicolumn{4}{|c|}{ Gender, $n(\%)$} & \multirow{3}{*}{$<0.001$} \\
\hline Female & $190(26.84)$ & $26(12.15)$ & $164(33.20)$ & \\
\hline Male & $518(73.16)$ & $188(87.85)$ & $330(66.80)$ & \\
\hline \multicolumn{4}{|c|}{ Smoking Status, $n(\%)$} & \multirow{4}{*}{0.017} \\
\hline Never smoker & $448(63.28)$ & $121(56.54)$ & $327(66.19)$ & \\
\hline Former smoker & $27(3.81)$ & $13(6.07)$ & $14(2.83)$ & \\
\hline Current smoker & $233(32.91)$ & $80(37.38)$ & $153(30.97)$ & \\
\hline \multicolumn{4}{|c|}{ Drinking Status, $n(\%)$} & \multirow{4}{*}{0.038} \\
\hline Never drinker & $443(62.57)$ & $106(49.53)$ & $337(68.22)$ & \\
\hline Former drinker & $10(1.41)$ & $5(2.34)$ & $5(1.01)$ & \\
\hline Current drinker & $255(36.02)$ & $103(48.13)$ & $152(30.77)$ & \\
\hline \multicolumn{4}{|c|}{ BMI $\left(\mathrm{kg} / \mathrm{m}^{2}\right), n(\%)$} & \multirow{3}{*}{$<0.001$} \\
\hline Normal & $266(37.57)$ & 38 (17.76) & $228(46.15)$ & \\
\hline Overweight/obesity & $442(62.43)$ & $176(82.24)$ & $266(53.85)$ & \\
\hline $\mathrm{SBP}(\mathrm{mm} \mathrm{Hg})$ & $127.49 \pm 18.70$ & $148.38 \pm 15.40$ & $118.44 \pm 11.30$ & $<0.001$ \\
\hline DBP (mm Hg) & $82.00 \pm 13.48$ & $96.91 \pm 9.93$ & $75.53 \pm 8.93$ & $<0.001$ \\
\hline $\mathrm{TC}(\mathrm{mmol} / \mathrm{L})$ & $5.14 \pm 0.95$ & $5.35 \pm 0.96$ & $5.05 \pm 0.93$ & $<0.001$ \\
\hline $\mathrm{TG}(\mathrm{mmol} / \mathrm{L}) *$ & $1.13(0.75,1.73)$ & $1.39(0.97,2.11)$ & $1.02(0.70,1.47)$ & $<0.001$ \\
\hline HDL-C (mmol/L) & $1.34 \pm 0.33$ & $1.31 \pm 0.33$ & $1.35 \pm 0.33$ & 0.132 \\
\hline LDL-C (mmol/L) & $2.97 \pm 0.94$ & $3.10 \pm 0.99$ & $2.92 \pm 0.91$ & 0.019 \\
\hline FBG $(\mathrm{mmol} / \mathrm{L})$ & $5.29 \pm 0.93$ & $5.54 \pm 1.07$ & $5.19 \pm 0.84$ & $<0.001$ \\
\hline
\end{tabular}

Abbreviations: BMI, body mass index; SBP, systolic blood pressure; DBP, diastolic blood pressure; FBG, fasting blood glucose; TC, cholesterol; TG, triglycerides; HDL-C, high-density lipoprotein cholesterol; LDL-C, low-density lipoprotein cholesterol. * Values are expressed as median and range. 


\subsection{Data Collection and Definitions}

We used a self-administered questionnaire to collect data on demographic characteristics, smoking and drinking status, and other health-related information. Smoking status was categorized as current smokers (smoking during the last one year or quit smoking less than six months ago), former smokers (quit smoking more than six months ago), or non-smokers (never smoke). Drinking status were categorized as current drinkers (at least two times/week for men and one time/week for women), former drinkers (quit drinking more than six months ago), or non-drinkers (never drink).

Body weight, height, and waist circumference were measured using a standard scale with light clothing and barefoot. Body mass index (BMI) was calculated as weight in kilograms divided by the square of height in meters $\left(\mathrm{kg} / \mathrm{m}^{2}\right)$. Overweight/obesity was defined as a BMI $\geqslant 24$ according to the Guidelines on the Prevention and Management of Overweight and Obesity in Adults: China [23]. Blood pressure was measured according to standardized procedural guidelines [24] while subjects were in the sitting position after $15 \mathrm{~min}$ of rest using standardized mercuric-column sphygmomanometer with appropriate adult cuff size by a carefully trained nurse. Systolic blood pressure (SBP) and diastolic blood pressure (DBP) were determined by the first and the fifth Korotkoff sounds. The average of three consecutive measurements to the nearest $2 \mathrm{mmHg}$ was recorded, with a time interval of at least two minutes. All participants were requested not to consume tea, coffee, alcohol, or tobacco, and to exercise for at least $30 \mathrm{~min}$ before measuring their blood pressure. Essential hypertension was regarded as the mean SBP at least $140 \mathrm{mmHg}$ and/or DBP at least $90 \mathrm{mmHg}$ and/or currently receiving treatment for hypertension. Normotension was regarded as the mean SBP/DBP at most 120/80 $\mathrm{mmHg}$ and with no history of hypertension.

The concentrations of triglyceride (TG), cholesterol (TC), high density lipoprotein (HDL), low density lipoprotein (LDL), and fasting blood glucose (FBG) were determined by enzymatic method using a Hitachi Autoanalyzer (Type 7170A; Hitachi Ltd., Tokyo, Japan) [25].

\subsection{Genotyping}

Genomic DNA was extracted from buccal samples using QiAamp DNA Mini Kit (Qiagen, Valencia, CA, USA). The genotypes of the MTHFR C677T were determined by a TaqMan assay, which has been detailed in our previous paper [7].

\subsection{Statistical Analysis}

Differences in the distribution of baseline characteristics between hypertensive and normotensive groups were tested using student's t-test for continuous variables (SBP, DBP, TC, TG, HDL, LDL, and FBG) and chi-square test for categorical variables (age, gender, smoking status, drinking status, and BMI). All of the continuous variables were tested for normality before Student's t-test, and those non-normally distributed variables were log-transformed to reach normality and variance homogeneity. Logistic regression analysis was used to examine the associations of age, gender, BMI, drinking, and smoking status with hypertension susceptibility. We coded age $\leqslant 45$ years $=0$, and age $>45$ years $=1$ (the mean age of the study subjects was 45.60 years); normal weight $=0$, and overweight/obesity $=1$. As the number of former-drinkers and former-smokers were too small to deduce valid results, we coded non-drinkers $=0$, ever-drinkers (current-drinkers and former-drinkers) $=1$, and non-smokers $=0$, ever-smokers (current-smokers and former-smokers) $=1$. A goodness of fit chi-square test was used to evaluate whether the genotypic distribution of the MTHFR C677T polymorphism was in accordance with Hardy-Weinberg equilibrium. We also used logistic regression analysis to examine the potential effects of the MTHFR C677T polymorphism on hypertension risk under five genetic models (homozygous codominant, heterozygous codominant, dominant, recessive, and allelic models). Then, we used the methods suggested by Thakkinstian et al. to select the most appropriate genetic model [26].

Subsequently, multivariable-adjusted stratified analyses were used to explore potential gene-environmental interactions based on the most appropriate genetic model. The MTHFR C677T polymorphism was dichotomized under dominant genetic model (the selected genetic model) in which TT and CT genotypes were combined, and we use the combined genotype as the "at risk" genotype 
for easy interpretation. Similarly, environmental characteristics were dichotomized by appropriate grouping noted above. Furthermore, relative excess risk due to interaction (RERI) and corresponding $95 \%$ confidence interval (CI) were calculated to evaluate the presence of interactions on the additive scale. The RERI is a measure of difference in excessive relative risks, and we calculated RERI and its 95\% CI using an Excel sheet downloaded from Epidemiological net [27]. If absent an interaction effect, RERI $=0$; if presenting a positive interaction, RERI $>0$; and if presenting a negative interaction, RERI $<0$. Linear regression analysis was also used to examine the association between age and blood pressure in each MTHFR C677T genotype group. In addition to the calculations of RERI and its $95 \%$ CI, all other statistical analyses were conducted using SAS software (version 9.2, SAS Institute Inc., Cary, NC, USA). A two tailed $p$ value less than 0.05 was taken as statistically significant.

\section{Results}

\subsection{General Characteristics of the Study Population}

A total of 708 subjects including 518 males and 190 females were finally included in the present study. Table 1 summarizes the baseline characteristics of these participants. The mean age of the study population was $45.60 \pm 11.03$ years. Compared with the normotensive controls, hypertensive individuals had significantly higher SBP, DBP, TG, TC, LDL, and FBG levels, and they were more likely to be older, men, overweight/obese, former smokers, and ever-drinkers (all $p<0.05$ ).

\subsection{Association between Environmental Factors and Hypertension Susceptibility}

Table 2 shows the results of univariate and multivariate logistic regression analyses for hypertension in relation to environmental factors including age, gender, BMI, and smoking and drinking status. In the univariate model, age $>45$ years, being male, overweight/obesity, ever-smokers, and ever-drinkers were significantly associated with an increased risk of hypertension $(p=0.038$ to $<0.001$ ). After adjustment for multiple covariates, the association of age $>45$ years, being male, overweight/obesity, and ever-drinkers with hypertension was still statistically significant with an OR of 2.63 (95\% (CI): 1.84-3.76, $p<0.001$ ), 1.81 (95\% CI: 1.08-3.04, $p=0.025)$, 2.78 (95\% CI: 1.83-4.22, $p<0.001$ ), and 1.60 (95\% CI: 1.10-2.33, $p=0.015)$, respectively. However, the relationship of smoking status with hypertension failed to reach significance $(p=0.743)$.

Table 2. Associations of age, gender, BMI, smoking, and drinking status with the risk of essential hypertension.

\begin{tabular}{|c|c|c|c|c|c|c|}
\hline Characteristics & Hypertensive & Normotensive & Crude OR $(95 \%$ CI) & $p$-Value & Adjusted OR (95\% CI) & $p$-Value \\
\hline \multicolumn{6}{|l|}{ Age } & \multirow[b]{2}{*}{$<0.001$} \\
\hline$\leqslant 45$ & 66 & 284 & 1.0 (reference) & & 1.0 (reference) & \\
\hline \multicolumn{6}{|c|}{ Gender } & \multirow[b]{2}{*}{0.025} \\
\hline Female & 26 & 164 & 1.0 (reference) & & 1.0 (reference) & \\
\hline Normal & 38 & 228 & 1.0 (reference) & & 1.0 (reference) & \multirow[t]{2}{*}{$<0.001$} \\
\hline Overweight/Obesity & 176 & 266 & $3.97(2.68-5.88)$ & $<0.001$ & $2.78(1.83-4.22)^{\mathrm{c}}$ & \\
\hline \multicolumn{6}{|c|}{ Smoking status } & \multirow[b]{2}{*}{0.743} \\
\hline Non-smokers & 119 & 327 & 1.0 (reference) & & 1.0 (reference) & \\
\hline Ever-drinkers & 109 & 157 & $2.23(1.61-3.09)$ & $<0.001$ & $1.60(1.10-2.33)^{\mathrm{e}}$ & 0.015 \\
\hline
\end{tabular}

Abbreviations: BMI, body mass index; OR, odds ratio; CI, confidence interval. Adjusted OR: ${ }^{a}$ adjusted for gender, BMI and smoking, drinking status; ${ }^{b}$ adjusted for age, BMI and smoking, drinking status; ${ }^{c}$ adjusted for age, gender and smoking, drinking status; ${ }^{\mathrm{d}}$ adjusted for age, gender, BMI and drinking status; ${ }^{\mathrm{e}}$ adjusted for age, gender, BMI and smoking status. $p$-Value $<0.05$ was considered statistically significant. 


\subsection{Association between MTHFR C677T Polymorphism and Hypertension Susceptibility}

Genotypic and allelic frequencies for the MTHFR C677T polymorphism are summarized in Table 3. The genotypic distribution of the polymorphism among the study population was in accordance with the Hardy-Weinberg equilibrium $(p=0.20)$. The frequency of the MTHFR 677T allele in the hypertensive group $(60.77 \%)$ was significantly higher than the normotensive group $(53.76 \%)(p=0.004)$. We further investigated the associations of the MTHFR C677T polymorphism with hypertension risk using the unconditional logistic regression analysis under five genetic models. In the univariate analysis, the MTHFR C677T polymorphism was significantly associated with hypertension under the homozygous co-dominant, dominant, and allelic models. After adjustments for age, gender, BMI, and smoking and drinking status, significant association was still observed in homozygous co-dominant ( $\mathrm{OR}=1.81$, $95 \% \mathrm{CI}=1.10-2.98, p=0.020)$ and dominant $(\mathrm{OR}=1.64,95 \% \mathrm{CI}=1.05-2.55, p=0.029)$ models.

Table 3. Association of the MTHFR C677T polymorphism with risk of essential hypertension.

\begin{tabular}{|c|c|c|c|c|c|c|}
\hline $\begin{array}{l}\text { MTHFR } \\
\text { C677T }\end{array}$ & $\begin{array}{c}\text { Hypertension, } \\
n(\%)\end{array}$ & $\begin{array}{c}\text { Normotensive, } \\
n(\%)\end{array}$ & $\begin{array}{c}\text { Crude OR } \\
(95 \% \mathrm{CI})\end{array}$ & $p$-Value & $\begin{array}{l}\text { Adjusted OR } \\
(95 \% \text { CI })\end{array}$ & $p$-Value \\
\hline \multicolumn{7}{|c|}{ Codominant } \\
\hline $\mathrm{CC}$ & 37 (17.29) & 119 (24.09) & 1.0 (reference) & & 1.0 (reference) & \\
\hline $\mathrm{CT}$ & $102(47.66)$ & $234(47.37)$ & $1.40(0.91-2.17)$ & 0.129 & $1.53(0.96-2.45)$ & 0.075 \\
\hline $\mathrm{TT}$ & $75(35.05)$ & $141(28.54)$ & $1.71(1.08-2.72)$ & 0.023 & $1.81(1.10-2.98)$ & 0.020 \\
\hline \multicolumn{7}{|c|}{ Dominant } \\
\hline $\mathrm{CC}$ & $37(17.29)$ & 119 (24.09) & 1.0 (reference) & & 1.0 (reference) & \\
\hline $\mathrm{CT}+\mathrm{TT}$ & $177(82.71)$ & $375(75.91)$ & $1.52(1.01-2.29)$ & 0.046 & $1.64(1.05-2.55)$ & 0.029 \\
\hline \multicolumn{7}{|c|}{ Recessive } \\
\hline $\mathrm{CC}+\mathrm{CT}$ & $139(64.95)$ & $353(71.46)$ & 1.0 (reference) & & 1.0 (reference) & \\
\hline $\mathrm{TT}$ & $75(35.05)$ & $141(28.54)$ & $1.35(0.96-1.90)$ & 0.085 & $1.34(0.93-1.94)$ & 0.120 \\
\hline \multicolumn{7}{|c|}{ Allele } \\
\hline $\mathrm{C}$ & $176(41.12)$ & 472 (47.77) & 1.0 (reference) & & & \\
\hline $\mathrm{T}$ & $252(58.88)$ & $516(52.23)$ & $1.31(1.04-1.65)$ & 0.021 & & \\
\hline
\end{tabular}

\subsection{Interaction Effects of the MTHFR C677T Polymorphism with Environmental Factors on Hypertension Susceptibility}

Table 4 shows the joint effects of the MTHFR C677T polymorphism with dichotomous age, gender, BMI, smoking status, and drinking status on hypertension risk. Compared with younger subjects with CC genotype, the hypertension risk among subjects who were older and carried the "at risk" genotype $(\mathrm{OR}=4.08,95 \% \mathrm{CI}=1.95-8.54, p<0.001)$ was much greater than those who were older with CC genotype ( $\mathrm{OR}=2.36,95 \% \mathrm{CI}=1.02-5.47)$ and among subjects who were younger with the "at risk" genotype $(\mathrm{OR}=1.46,95 \% \mathrm{CI}=0.69-3.12)$. The corresponding RERI was $1.26(95 \% \mathrm{CI}=-0.33-2.85$, $p=0.103)$, suggesting a marginally significant interaction on the additive level. 
Table 4. Interaction effects of the MTHFR C677T polymorphism with age, sex, BMI, drinking, and smoking status on hypertension susceptibility.

\begin{tabular}{|c|c|c|c|c|c|}
\hline Genotype & $\begin{array}{l}\text { Demographic and } \\
\text { Lifestyle Factor }\end{array}$ & $\begin{array}{l}\text { Adjusted OR * } \\
(95 \% \text { CI })\end{array}$ & $p$-Value & RERI (95\% CI) & $p$-Value \\
\hline \multicolumn{6}{|c|}{ Age } \\
\hline $\begin{array}{c}\mathrm{CC} \\
\mathrm{CT}+\mathrm{TT}\end{array}$ & $\leqslant 45$ & $\begin{array}{c}1.0 \text { (reference) } \\
1.46(0.69-3.12)\end{array}$ & 0.325 & \multirow{2}{*}{$1.26(-0.33-2.85)$} & \multirow{2}{*}{0.103} \\
\hline $\begin{array}{c}\mathrm{CC} \\
\mathrm{CT}+\mathrm{TT}\end{array}$ & $>45$ & $\begin{array}{l}2.36(1.02-5.47) \\
4.08(1.95-8.54)\end{array}$ & $\begin{array}{c}0.045 \\
<0.001\end{array}$ & & \\
\hline \multicolumn{6}{|c|}{ Sex } \\
\hline $\begin{array}{c}\mathrm{CC} \\
\mathrm{CT}+\mathrm{TT}\end{array}$ & Female & $\begin{array}{c}1.0 \text { (reference) } \\
2.77(0.77-9.99)\end{array}$ & 0.119 & \multirow{2}{*}{$-0.27(-2.85-2.32)$} & \multirow{2}{*}{0.818} \\
\hline $\begin{array}{c}\mathrm{CC} \\
\mathrm{CT}+\mathrm{TT}\end{array}$ & Male & $\begin{array}{c}2.98 \\
(0.82-10.85) \\
4.48 \\
(1.29-15.55)\end{array}$ & $\begin{array}{l}0.098 \\
0.018\end{array}$ & & \\
\hline \multicolumn{6}{|c|}{ BMI } \\
\hline $\begin{array}{c}\mathrm{CC} \\
\mathrm{CT}+\mathrm{TT}\end{array}$ & Normal weight & $\begin{array}{c}1.0 \text { (reference) } \\
1.34(0.56-3.19)\end{array}$ & 0.506 & \multirow{2}{*}{$1.33(-0.15-2.80)$} & \multirow{2}{*}{0.084} \\
\hline $\begin{array}{c}\mathrm{CC} \\
\mathrm{CT}+\mathrm{TT}\end{array}$ & Overweight/obesity & $\begin{array}{l}2.23(0.91-5.48) \\
3.90(1.74-8.72)\end{array}$ & $\begin{array}{l}0.079 \\
0.001\end{array}$ & & \\
\hline \multicolumn{6}{|c|}{ Drinking status } \\
\hline $\begin{array}{c}\mathrm{CC} \\
\mathrm{CT}+\mathrm{TT}\end{array}$ & Non-drinkers & $\begin{array}{c}1.0 \text { (reference) } \\
1.63(0.89-2.97)\end{array}$ & 0.111 & \multirow{2}{*}{$0.40(-0.92-1.72)$} & \multirow{2}{*}{0.569} \\
\hline $\begin{array}{c}\mathrm{CC} \\
\mathrm{CT}+\mathrm{TT}\end{array}$ & Ever-drinkers & $\begin{array}{l}1.59(0.72-3.55) \\
2.62(1.39-4.96)\end{array}$ & $\begin{array}{l}0.255 \\
0.003\end{array}$ & & \\
\hline \multicolumn{6}{|c|}{ Smoking status } \\
\hline $\begin{array}{c}\mathrm{CC} \\
\mathrm{CT}+\mathrm{TT}\end{array}$ & Non-smokers & $\begin{array}{c}1.0 \text { (reference) } \\
2.07(1.17-3.65)\end{array}$ & 0.012 & \multirow{2}{*}{$-0.88(-2.51-0.75)$} & \multirow{2}{*}{0.271} \\
\hline $\begin{array}{c}\mathrm{CC} \\
\mathrm{CT}+\mathrm{TT}\end{array}$ & Ever-smokers & $\begin{array}{l}1.70(0.74-3.88) \\
1.88(1.04-3.42)\end{array}$ & $\begin{array}{l}0.211 \\
0.038\end{array}$ & & \\
\hline
\end{tabular}

Abbreviations: MTHFR, methylenetetrahydrofolate reductase; BMI, body mass index; OR, odds ratio; $\mathrm{CI}$, confidence interval; RERI, relative excess risk due to interaction. * Joint ORs for age and genotype was adjusted by sex; BMI, drinking and smoking status; joint ORs for gender and genotype was adjusted by age, BMI, drinking and smoking status; joint ORs for BMI and genotype were adjusted by age, sex, drinking, and smoking status; joint ORs for drinking status and genotype was adjusted by age, sex, BMI and smoking status; joint ORs for smoking and genotype were adjusted by age, sex, and drinking status. $p$-Value $<0.05$ was considered statistically significant.

In addition, we found that the strongest effects of age on blood pressure levels was in the 677TT genotype carriers, followed by 677CT genotype and 677CC genotype carriers (Figure 1). Similarly, there were some indications for an interaction between the polymorphism and being overweight/obesity. The joint OR for overweight/obesity and the "at risk" genotype was $3.90(95 \% \mathrm{CI}=1.74-8.72, p=0.001)$, which is greater than the independent $\mathrm{ORs}$ for the "at risk" genotype $(\mathrm{OR}=1.34,95 \% \mathrm{CI}=0.56-3.19)$ and overweight/obesity $(\mathrm{OR}=2.23,95 \% \mathrm{CI}=0.91-5.48)$, with an RERI of $1.33(95 \% \mathrm{CI}=-0.15-2.80$, $p=0.084$ ). No apparent combined effect between sex, drinking status, smoking status, and the polymorphism was found. 


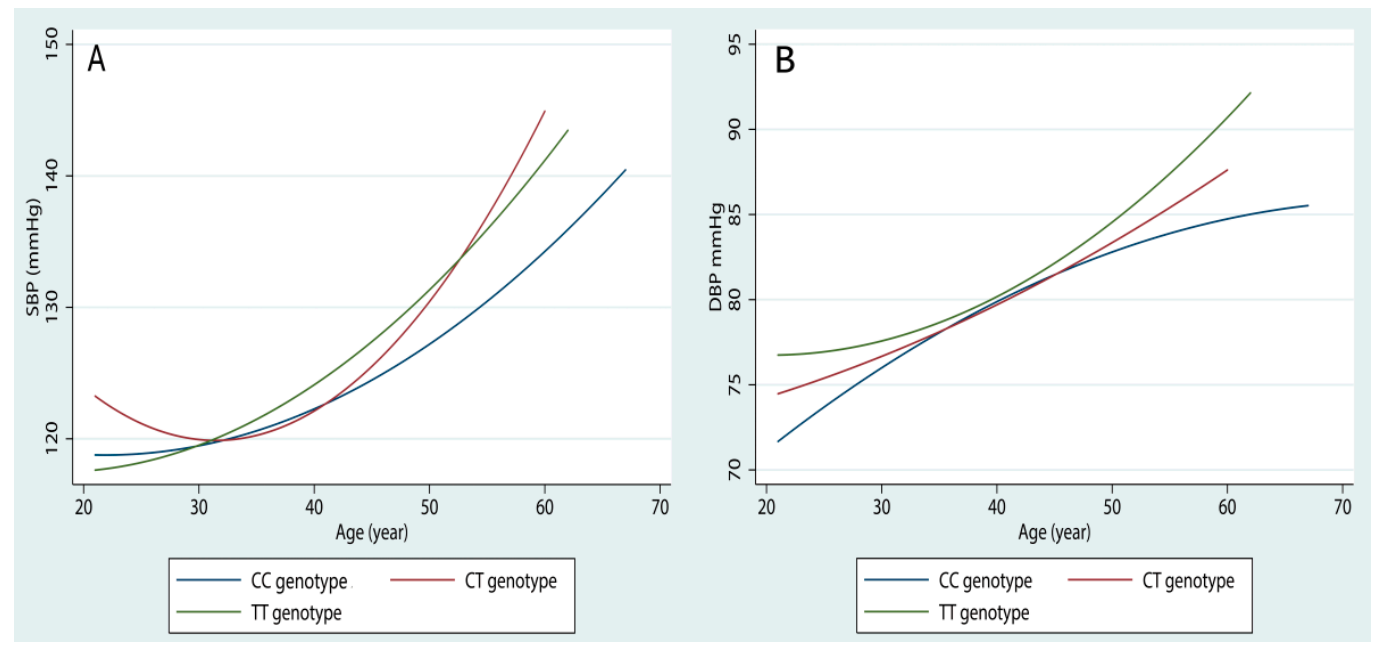

Figure 1. The effects of age on SBP (A) and DBP (B) levels in different MTHFR C677T genotype groups.

\section{Discussion}

In this study we systematically explored the effects of the MTHFR C677T polymorphism, several environmental factors, and their interactions on the development of hypertension among the Northern Chinese Han population. Participants with older age, high BMI, smoking habits, drinking habits, or carrying the $677 \mathrm{~T}$ allele were at increased risk of hypertension. Furthermore, we observed some indications for interactions of the MTHFR C677T mutant genotype with older age and being overweight/obesity.

Numerous prior epidemiological studies have investigated the association of the MTHFR C677T polymorphism with hypertension, but the results were controversial [12,28]. A recent meta-analysis by Niu et al. included nine studies conducted among the Chinese population, four of which reported a significant association between the C677T polymorphism and essential hypertension, but the remaining five did not [28]. Our research group also demonstrated differences in hypertension risk in relation to the polymorphism among different populations worldwide [12]. In the present study, we observed that the 677T allele was significantly associated with an increased risk of hypertension in the Northern Chinese Han population. Many factors may contribute to the phenomenon that the MTHFR C677T polymorphism is related to hypertension in one population, but not in another population. Among them, gene-environment interaction could not be neglected as our current understanding of pathogenesis of hypertension indicates a multifactorial and multistep process including various genetic and environmental factors.

We further explored possible interaction effects of the MTHFR C677T polymorphism with several environmental factors, and found that the joint effects of the "at risk" genotype with older age and being overweight/obesity were greater than the sum of their individual effects. The RERIs for the interaction of older age and being overweight/obesity with the "at risk" genotype were 1.26 $(95 \% \mathrm{CI}=-0.33-2.85)$ and $1.33(95 \% \mathrm{CI}=-0.15-2.80)$, respectively, indicating an OR that is 1.26 and 1.33 times higher, respectively, as a result of the interaction. Notably, the calculated lower confidence limits for both RERIs were less than, but close, to zero, meaning that the interactions were marginally significant. One possible explanation for the marginally significant interaction might be the relatively small sample size of the present study, especially in some subgroups.

The precise mechanisms by which age and the MTHFR C677T polymorphism interact to influence the development of hypertension remain unclear. However, both older age and the 677T allele can cause hyperhomocysteinemia and aberrant DNA methylation [10,29-31], which are significantly associated with hypertension [9,11]. Furthermore, an interaction between age and the MTHFR C677T polymorphism on plasma homocysteine concentrations has been reported [32]. Therefore, the 
synergistic effect of the MTHFR C677T polymorphism and age on hypertension may be partially due to their interactive effects on homocysteine concentrations and DNA status. The age-gene synergism observed in this study may be biologically plausible and expected.

Consistent with our findings on the potential interaction between the polymorphism and being overweight/obesity, a large population-based case-control study among Chinese population by Xi et al. observed that the MTHFR C677T polymorphism was significantly associated with hypertension only in obese children [17]. Overweight/obesity can increase the risk of hypertension by activating the sympathetic nervous system and renin-angiotensin system, inducing insulin resistance, and impairing endothelial function [33]. Some of these pathophysiological mechanisms such as insulin resistance and endothelial dysfunction are shared by hyperhomocysteinemia in causing hypertension [9]. Additionally, several epidemiological studies observed that overweight/obesity subjects had higher homocysteine and/or lower folate levels than normal weight ones [34,35]. Furthermore, a body of evidence has suggested that elevated homocysteine levels might cause the development of being overweight/obesity via epigenetic control gene expression in the regulation of body fat storage [36,37]. Furthermore, a recent study by Yin et al. showed that the MTHFR C677T polymorphism interacted with overweight/obesity to modulate serum lipid levels [38]. In the present study, we also evaluated possible joint effects of the polymorphism and being overweight/obesity on serum lipid levels and found that subjects carrying the "at risk" genotype and being overweight/obesity have significantly higher TC and TG levels and lower HDL levels than other subjects (data not shown). Dyslipidemia has a causal relationship with hypertension. So we inferred that the interaction of the MTHFR C677T polymorphism and overweight/obesity on dyslipidemia may be a partial reason for their joint effects on hypertension found in this study. In spite of this, the biological mechanisms by which overweight/obesity modifies the relationship between the MTHFR C677T polymorphism and hypertension risk remain unclear and just can be speculated. Further studies are therefore still warranted to investigate the precise mechanism of the interaction in the pathogenesis of hypertension.

The relationship between cigarette smoking and hypertension is controversial. Some investigators reported that cigarette smoking can increase the risk of hypertension, while others reported that it was associated with reduced hypertension risk, and some found no direct association between them [39-41]. However, cigarette smoking was demonstrated to play a role in modifying the effects of some genes on hypertension [42]. For example, Yin et al. observed no association between cigarette smoking and hypertension in a Guangxi Bai Ku Yao population; however, they found that cigarette smoking showed interaction with the MTHFR C677T polymorphism to affect blood pressure levels [42]. In contrast, our results showed no interaction between cigarette smoking and the polymorphism. Alcohol consumption (especially excessive alcohol consumption) is a known risk factor for hypertension, which was also confirmed in our study. The intermediate metabolites of alcohol can change genes directly and modulate their expression via epigenetic mechanisms [43]. Therefore, interaction between alcohol drinking and genes may be biologically plausible. Another analysis by Yin et al. found interactive effects of alcohol consumption with the MTHFR C677T polymorphism on hypertension [43], which was different from our findings. The discrepancies between our findings and those reported by Yin et al. [42,43] can be caused by many factors, including differences in ethnic background (Bai Ku Yao [42,43] vs. Han (the present study)), sample size, dietary habits, and other environmental exposures.

In interpreting the findings of our study, several limitations need to be considered. Firstly, this study used a cross-sectional design, which precludes causal inference. Secondly, the study subjects were recruited from only one hospital, which compromises the representation of the general population and our findings may not be generalizable to the whole Chinese population, although the genotype distribution of the polymorphism in our study subjects complied with the Hardy-Weinberg equilibrium. Thirdly, selection bias is possible because the majority of the study participants were workers in the Dagang Oil Field, and there were significantly more male subjects than females. The significant gender difference in the number of study subjects also makes it difficult to draw conclusions regarding gender. 
Fourthly, because we used a questionnaire to collect personal exposure information (such as smoking and drinking), the responses might be influenced by the participant's memory, so recall bias cannot be excluded. Fifthly, some information on relevant potential confounders, such as menopause status, dietary habits (especially folate and riboflavin intake), physical activity, and other genes were not included and controlled in this study. This could have affected the accuracy of our estimates. Despite these limitations, our study still has several apparent advantages. First, the study was carried out in a northern region where 677TT genotype frequency was high according to our previous findings [7], which guarantees sufficient number of 677TT genotype carriers to enhance the statistical power and to save the research costs. Second, all participants were of Han nationality, which reduces the potential effects of population stratification and improves the validity of statistical analysis. Third, to the best of our knowledge, this is the first study to explore and report the joint effects of the MTHFR C677T polymorphism with age, being overweight/obesity, gender, alcohol drinking, and cigarette smoking on hypertension predisposition.

\section{Conclusions}

In summary, the results of the present study suggest that the MTHFR 677T allele is associated with an increased risk of hypertension. Additionally, these results suggest a potential synergistic effect of the polymorphism with age and BMI on hypertension susceptibility. Our findings provide a further insight on the gene-environment relationships involved in hypertension pathogenesis. However, future large, well-designed studies in Chinese and other populations, as well as mechanistic studies, are needed to validate our findings, especially considering that the interactions observed in our study were marginally significant.

Acknowledgments: We gratefully acknowledge the assistance and cooperation of the faculty and staff of Dagang Oil Field Hospital and thank all of the participants in our study. We also thank Prarthana Nair in China Medical University for her elaborative reviewing of this manuscript and useful suggestions on language use.

Author Contributions: Shujun Fan, Boyi Yang, Guifan Sun conceived and designed the experiments; Xueyuan Zhi, Yanxun Wang and Jian Wei performed the experiments; Shujun Fan, Boyi Yang analyzed the data; Quanmei Zheng contributed reagents/materials/analysis tools; Shujun Fan and Guifan Sun wrote the paper.

Conflicts of Interest: The authors declare no conflict of interest.

\section{Abbreviations}

The following abbreviations are used in this manuscript:

$\begin{array}{ll}\text { BMI } & \text { body mass index } \\ \text { CI } & \text { confidence index } \\ \text { DBP } & \text { diastolic blood pressure } \\ \text { FBG } & \text { fasting blood glucose } \\ \text { GWAS } & \text { genome-wide association study } \\ \text { HDL-C } & \text { high-density lipoprotein } \\ \text { LDL-C } & \text { low-density lipoprotein } \\ \text { MTHFR } & \text { methylenetetrahydrofolate reductase } \\ \text { OR } & \text { odds ratio } \\ \text { RERI } & \text { relative excess risk due to interaction } \\ \text { SBP } & \text { systolic blood pressure } \\ \text { TC } & \text { total cholesterol } \\ \text { TG } & \text { triglyceride }\end{array}$

\section{References}

1. World Health Organization. Toward a Healthy and Harmonious Life in China: Stemming the Rising Tide of Non-Communicable Diseases; WHO: Geneva, Switzerland, 2011. 
2. Biino, G.; Parati, G.; Concas, M.P.; Adamo, M.; Angius, A.; Vaccargiu, S.; Pirastu, M. Environmental and genetic contribution to hypertension prevalence: Data from an epidemiological survey on Sardinian genetic isolates. PLoS ONE 2013, 8, e59612. [CrossRef] [PubMed]

3. Poulter, N.R.; Prabhakaran, D.; Caulfield, M. Hypertension. Lancet 2015, 386, 801-812. [CrossRef]

4. Sung, Y.J.; de Las Fuentes, L.; Schwander, K.L.; Simino, J.; Rao, D.C. Gene-smoking interactions identify several novel blood pressure loci in the Framingham Heart Study. Am. J. Hypertens. 2015, 28, 343-354. [CrossRef] [PubMed]

5. Frazer, K.A.; Murray, S.S.; Schork, N.J.; Topol, E.J. Human genetic variation and its contribution to complex traits. Nat. Rev. Genet. 2009, 10, 241-251. [CrossRef] [PubMed]

6. Newton-Cheh, C.; Johnson, T.; Gateva, V.; Tobin, M.D.; Bochud, M.; Coin, L.; Najjar, S.S.; Zhao, J.H.; Heath, S.C.; Eyheramendy, S.; et al. Genome-wide association study identifies eight loci associated with blood pressure. Nat. Genet. 2009, 41, 666-676. [CrossRef] [PubMed]

7. Yang, B.; Liu, Y.; Li, Y.; Fan, S.; Zhi, X.; Lu, X.; Wang, D.; Zheng, Q.; Wang, Y.; Wang, Y.; et al. Geographical distribution of MTHFR C677T, A1298C and MTRR A66G gene polymorphisms in China: Findings from 15,357 adults of Han nationality. PLoS ONE 2013, 8, e57917. [CrossRef] [PubMed]

8. Rozen, R. Genetic predisposition to hyperhomocysteinemia: Deficiency of methylenetetrahydrofolate reductase (MTHFR). Thromb. Haemost. 1997, 78, 523-526. [PubMed]

9. Stehouwer, C.D.; van Guldener, C. Does homocysteine cause hypertension? Clin. Chem. Lab. Med. 2003, 41, 1408-1411. [CrossRef] [PubMed]

10. Weiner, A.S.; Boyarskikh, U.A.; Voronina, E.N.; Mishukova, O.V.; Filipenko, M.L. Methylenetetrahydrofolate reductase $\mathrm{C} 677 \mathrm{~T}$ and methionine synthase $\mathrm{A} 2756 \mathrm{G}$ polymorphisms influence on leukocyte genomic DNA methylation level. Gene 2014, 533, 168-172. [CrossRef] [PubMed]

11. Kato, N.; Loh, M.; Takeuchi, F.; Verweij, N.; Wang, X.; Zhang, W.; Kelly, T.N.; Saleheen, D.; Lehen, B.; Mateo Leach, I.; et al. Trans-ancestry genome-wide association study identifies 12 genetic loci influencing blood pressure and implicates a role for DNA methylation. Nat. Genet. 2015, 47, 1282-1293. [CrossRef] [PubMed]

12. Yang, B.Y.; Fan, S.J.; Zhi, X.Y.; Li, Y.F.; Liu, Y.Y.; Wang, D.; He, M.; Hou, Y.Y.; Zheng, Q.M.; Sun, G.F. Associations of MTHFR gene polymorphisms with hypertension and hypertension in pregnancy: A meta-analysis from 114 studies with 15411 cases and 21970 controls. PLoS ONE 2014, 9, e87497. [CrossRef] [PubMed]

13. Ehret, G.B.; Munroe, P.B.; Rice, K.M.; Bochud, M.; Johnson, A.D.; Chasman, D.I.; Smith, A.V.; Tobin, M.D.; Verwoert, G.C.; Hwang, S.J.; et al. Genetic variants in novel pathways influence blood pressure and cardiovascular disease risk. Nature 2011, 478, 103-109. [CrossRef] [PubMed]

14. Kato, N.; Takeuchi, F.; Tabara, Y.; Kelly, T.N.; Go, M.J.; Sim, X.; Tay, W.T.; Chen, C.H.; Zhang, Y.; Yamamoto, K.; et al. Meta-analysis of genome-wide association studies identifies common variants associated with blood pressure variation in east Asians. Nat. Genet. 2011, 43, 531-538. [CrossRef] [PubMed]

15. Xi, B.; Shen, Y.; Reilly, K.H.; Wang, X.; Mi, J. Recapitulation of four hypertension susceptibility genes (CSK, CYP17A1, MTHFR, and FGF5) in East Asians. Metabolism 2013, 62, 196-203. [CrossRef] [PubMed]

16. Simino, J.; Sung, Y.J.; Kume, R.; Schwander, K.; Rao, D.C. Gene-alcohol interactions identify several novel blood pressure loci including a promising locus near SLC16A9. Front. Genet. 2013, 4, 277. [CrossRef] [PubMed]

17. Xi, B.; Zhao, X.; Chandak, G.R.; Shen, Y.; Cheng, H.; Hou, D.; Wang, X.; Mi, J. Influence of obesity on association between genetic variants identified by genome-wide association studies and hypertension risk in Chinese children. Am. J. Hypertens. 2013, 26, 990-996. [CrossRef] [PubMed]

18. Gatti, R.R.; Santos, P.S.; Sena, A.A.; Marangoni, K.; Araújo, M.A.; Goulart, L.R. The interaction of AGT and NOS3 gene polymorphisms with conventional risk factors increases predisposition to hypertension. J. Renin. Angiotensin Aldosterone Syst. 2013, 14, 360-368. [CrossRef] [PubMed]

19. Klerk, M.; Verhoef, P.; Clarke, R.; Blom, H.J.; Kok, F.J.; Schouten, E.G.; MTHFR Studies Collaboration Group. MTHFR $677 \mathrm{C} \rightarrow$ T polymorphism and risk of coronary heart disease: A meta-analysis. JAMA 2002, 288, 2023-2031. [PubMed]

20. Reilly, R.; McNulty, H.; Pentieva, K.; Strain, J.J.; Ward, M. MTHFR 677T genotype and disease risk: Is there a modulating role for B-vitamins? Proc. Nutr. Soc. 2014, 73, 47-56. [CrossRef] [PubMed] 
21. Wilson, C.P.; McNulty, H.; Ward, M.; Strain, J.J.; Trouton, T.G.; Hoeft, B.A.; Weber, P.; Roos, F.F.; Horigan, G.; McAnena, L.; et al. Blood pressure in treated hypertensive individuals with the MTHFR 677TT genotype is responsive to intervention with riboflavin: Findings of a targeted randomized trial. Hypertension 2013, 61, 1302-1308. [CrossRef] [PubMed]

22. Husemoen, L.L.; Thomsen, T.F.; Fenger, M.; Jørgensen, T. Effect of lifestyle factors on plasma total homocysteine concentrations in relation to MTHFR (C677T) genotype. Inter99 (7). Eur. J. Clin. Nutr. 2004, 58, 1142-1150. [CrossRef] [PubMed]

23. Working group on obesity problem in China (WGDC). The Guidelines on the Prevention and Management of Overweight and Obesity in Adults: China. Acta Nutr. Sin. 2004, 1, 1-4.

24. Kirkendall, W.M.; Feinleib, M.; Freis, E.D.; Mark, A.L. Recommendations for human blood pressure determination by sphygmomanometers. Subcommittee of the AHA Postgraduate Education Committee. Hypertension 1981, 3, 510A-519A. [CrossRef] [PubMed]

25. Yang, B.; Fan, S.; Zhi, X.; Wang, D.; Li, Y.; Wang, Y.; Wang, Y.; Wei, J.; Zheng, Q.; Sun, G. Associations of MTHFR C677T and MTRR A66G gene polymorphisms with metabolic syndrome: A case-control study in Northern China. Int. J. Mol. Sci. 2014, 15, 21687-21702. [CrossRef] [PubMed]

26. Thakkinstian, A.; McEvoy, M.; Minelli, C.; Gibson, P.; Hancox, B.; Duffy, D.; Thompson, J.; Hall, I.; Kaufman, J.; Leung, T.F.; et al. Systematic review and meta-analysis of the association between $\{$ beta\}2-adrenoceptor polymorphisms and asthma: A HuGE review. Am. J. Epidemiol. 2005, 162, 201-211. [CrossRef] [PubMed]

27. EpiNET: Epidemiological Net. Available online: http://epinet.se/Epidemiologicaltools.htm (accessed on 21 March 2015).

28. Niu, W.Q.; You, Y.G.; Qi, Y. Strong association of methylenetetrahydrofolate reductase gene C677T polymorphism with hypertension and hypertension-in-pregnancy in Chinese: A meta-analysis. J. Hum. Hypertens. 2012, 26, 259-267. [CrossRef] [PubMed]

29. Liu, X.D.; Gao, B.; Sun, D.; Shi, M.; Ma, Y.Y.; Liu, Z.R.; Wang, B.; Xu, X.; Xu, X.; Ji, Q.H.; et al. Prevalence of hyperhomocysteinemia and some of its major determinants in Shaanxi Province, China: A cross-sectional study. Br. J. Nutr. 2015, 113, 691-698. [CrossRef] [PubMed]

30. Yang, B.; Fan, S.; Zhi, X.; Wang, Y.; Wang, Y.; Zheng, Q.; Sun, G. Prevalence of hyperhomocysteinemia in China: A systematic review and meta-analysis. Nutrients 2014, 7, 74-90. [CrossRef] [PubMed]

31. Gomes, M.V.; Toffoli, L.V.; Arruda, D.W.; Soldera, L.M.; Pelosi, G.G.; Neves-Souza, R.D.; Freitas, E.R.; Castro, D.T.; Marguez, A.S. Age-related changes in the global DNA methylation profile of leukocytes are linked to nutrition but are not associated with the MTHFR C677T genotype or to functional capacities. PLOS ONE 2012, 7, e52570.

32. Selhub, J.; Jacques, P.F.; Wilson, P.W.; Rush, D.; Rosenberg, I.H. Vitamin status and intake as primary determinants of homocysteinemia in an elderly population. JAMA 1993, 270, 2693-2698. [CrossRef] [PubMed]

33. Kotchen, T.A. Obesity-related hypertension: Epidemiology, pathophysiology, and clinical management. Am. J. Hypertens. 2010, 23, 1170-1178. [CrossRef] [PubMed]

34. Marchesini, G.; Manini, R.; Bianchi, G.; Sassi, S.; Natale, S.; Chierici, S.; Visani, F.; Baraldi, L.; Forlani, G.; Melchionda, N. Homocysteine and psychological traits: A study in obesity. Nutrition 2002, 18, $403-407$. [CrossRef]

35. Martos, R.; Valle, M.; Morales, R.; Cañete, R.; Gavilan, M.I.; Sánchez-Margalet, V. Hyperhomocysteinemia correlates with insulin resistance and low-grade systemic inflammation in obese prepubertal children. Metabolism 2006, 55, 72-77. [CrossRef] [PubMed]

36. Terruzzi, I.; Senesi, P.; Fermo, I.; Lattuada, G.; Luzi, L. Are genetic variants of the methyl group metabolism enzymes risk factors predisposing to obesity? J. Endocrinol. Invest. 2007, 30, 747-753. [CrossRef] [PubMed]

37. Williams, K.T.; Schalinske, K.L. New insights into the regulation of methyl group and homocysteine metabolism. J. Nutr. 2007, 137, 311-314. [PubMed]

38. Yin, R.X.; Wu, D.F.; Miao, L.; Aung, L.H.; Cao, X.L.; Yan, T.T.; Long, X.J.; Liu, W.Y.; Zhang, L.; Li, M. Several genetic polymorphisms interact with overweight/obesity to influence serum lipid levels. Cardiovasc. Diabetol. 2012, 11, 123. [CrossRef] [PubMed]

39. Niskanen, L.; Laaksonen, D.E.; Nyyssönen, K.; Punnonen, K.; Valkonen, V.P.; Fuentes, R.; Tuomainen, T.P.; Salonen, R.; Salonen, J.T. Inflammation, abdominal obesity, and smoking as predictors of hypertension. Hypertension 2004, 44, 859-865. [CrossRef] [PubMed] 
40. Lee, D.H.; Ha, M.H.; Kim, J.R.; Jacobs, D.R., Jr. Effects of smoking cessation on changes in blood pressure and incidence of hypertension: A 4-year follow-up study. Hypertension 2001, 37, 194-198. [CrossRef] [PubMed]

41. Primatesta, P.; Falaschetti, E.; Gupta, S.; Marmot, M.G.; Poulter, N.R. Association between smoking and blood pressure: Evidence from the health survey for England. Hypertension 2001, 37, 187-193. [CrossRef] [PubMed]

42. Yin, R.X.; Wu, D.F.; Wu, J.Z.; Cao, X.L.; Aung, L.H.; Miao, L.; Long, X.J.; Liu, W.Y.; Zhang, L.; Li, M. Interactions of several lipid-related gene polymorphisms and cigarette smoking on blood pressure levels. Int. J. Biol. Sci. 2012, 8, 685-696. [CrossRef] [PubMed]

43. Yin, R.X.; Aung, L.H.; Long, X.J.; Yan, T.T.; Cao, X.L.; Huang, F.; Wu, J.Z.; Yang, D.Z.; Lin, W.X.; Pan, S.L. Interactions of several genetic polymorphisms and alcohol consumption on blood pressure levels. Biofactors 2015, 41, 339-351. [PubMed]

(C) 2016 by the authors; licensee MDPI, Basel, Switzerland. This article is an open access article distributed under the terms and conditions of the Creative Commons Attribution (CC-BY) license (http://creativecommons.org/licenses/by/4.0/). 